\title{
A String of Mistakes: The Importance of Cascade Analysis in Describing, Counting, and Preventing Medical Errors
}

Steven $H$. Woolf, $M D, M P H^{1}$

Anton J. Kuzel, MD, MHPE ${ }^{1}$

Susan M. Dovey, MPH, PbD ${ }^{2}$

Robert L. Pbillips, Jr, MD, MSPH ${ }^{2}$

'Department of Family Medicine, Virginia Commonwealth University, Richmond, Va

${ }^{2}$ Robert Graham Center: Policy Studies in Family Practice and Primary Care, American Academy of Family Physicians, Washington, DC

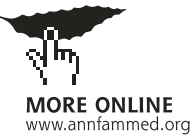

Conflict of interest: none reported

\section{CORRESPONDING AUTHOR}

Steven H. Woolf, MD, MPH

Department of Family Medicine

Virginia Commonwealth University

3712 Charles Stewart Dr

Fairfax, VA 22033

swoolf@vcu.edu

\begin{abstract}
BACKGROUND Notions about the most common errors in medicine currently rest on conjecture and weak epidemiologic evidence. We sought to determine whether cascade analysis is of value in clarifying the epidemiology and causes of errors and whether physician reports are sensitive to the impact of errors on patients.
\end{abstract}

METHODS Eighteen US family physicians participating in a 6-country international study filed 75 anonymous error reports. The narratives were examined to identify the chain of events and the predominant proximal errors. We tabulated the consequences to patients, both reported by physicians and inferred by investigators.

RESULTS A chain of errors was documented in $77 \%$ of incidents. Although $83 \%$ of the errors that ultimately occurred were mistakes in treatment or diagnosis, 2 of 3 were set in motion by errors in communication. Fully $80 \%$ of the errors that initiated cascades involved informational or personal miscommunication. Examples of informational miscommunication included communication breakdowns among colleagues and with patients (44\%), misinformation in the medical record (21\%), mishandling of patients' requests and messages (18\%), inaccessible medical records $(12 \%)$, and inadequate reminder systems $(5 \%)$. When asked whether the patient was harmed, physicians answered affirmatively in $43 \%$ of cases in which their narratives described harms. Psychological and emotional effects accounted for $17 \%$ of physician-reported consequences but $69 \%$ of investigator-inferred consequences.

CONCLuSIONS Cascade analysis of physicians' error reports is helpful in understanding the precipitant chain of events, but physicians provide incomplete information about how patients are affected. Miscommunication appears to play an important role in propagating diagnostic and treatment mistakes.

Ann Fam Med 2004;2:317-326 DOI: 10.1370/afm.126.

\section{INTRODUCTION}

The early years of the patient safety movement focused on the lowhanging fruit - the medical errors that are easiest to recognize and remedy (eg, adverse drug events, surgical mishaps). It is unclear, however, whether these errors are the most common or most harmful to patients. ${ }^{1}$ Properly measuring the incidence and morbidity of errors requires sound epidemiologic research, and the results and validity of such research depend greatly on how precisely errors are defined and the settings where the research is conducted.

Errors are difficult to measure, not only because of inadequate reporting and varied definitions, but also because most error incidents are not single acts but a chain of events. ${ }^{2}$ Prescribing the wrong dose of a drug may be counted as a single error and given a single name, such as a prescribing error, but the physician's prescribing error may have occurred because the medical record contained an incorrect body weight or because a laboratory report was missing. Researchers and administrators who ignore this complexity 
can produce skewed statistics and propagate imprecise notions about the anatomy, causes, and consequences of errors. This imprecision affects patients, clinicians, and policy makers, because it misplaces blame and resources on secondary culprits ${ }^{3}$ and diverts attention from fundamental problems and system redesigns that can more effectively enhance patient safety.,

A more thoughtful approach to the analysis of medical errors would make their complex anatomy explicit. Studying the cascade ${ }^{2,6}$ of events that constitute errors serves several purposes. First, it could provide a more accurate epidemiology of medical errors through an enhanced tabulation of errors and their causal relationships. Proximal errors that give rise to distal errors may be undercounted if only the distal errors are measured. Second, it could eschew blame by recognizing when errors in one setting are set in motion, if not made inevitable, by mistakes made elsewhere. Third, it could help identify root causes with system solutions rather than investing resources in the downstream errors that they propagate.

The epidemiology of medical errors is also compromised by inadequate data about the consequences to patients. The prevailing view that patients are primarily affected by improper drug prescriptions and surgical mistakes ${ }^{7}$ derives largely from medical record audits, ${ }^{8-10}$ a method that has been debated. ${ }^{11-17}$ Patients have a unique perspective on harms ${ }^{18}$ but are often unaware that errors have occurred or how their health was jeopardized. Physicians know about errors and some consequences, and thus voluntary or mandatory reporting has received attention, ${ }^{19}$ but its validity has undergone little scientific scrutiny.

A set of physician error reports, gathered as part of a 6-country international study of errors in primary care, gave us an opportunity to explore both issues at once: whether cascade analysis is of value in clarifying the causes of errors, and whether physician reports are sensitive to the impact of errors on patients. We examined these reports not because of their sample size (only 75 cases were examined) or generalizability to primary care; the errors that physicians choose to report are almost certainly not representative of all errors. Rather, our objective was a test of principle-to explore whether the cascade concept is of value in studying what occurs in medical errors-with the larger aim of future application to larger and more representative samples of medical errors.

\section{METHODS}

\section{International Study}

The LINNAEUS Collaboration, a group of investigators in 6 countries concerned with patient safety in primary care, launched the Primary Care International Study of Medical Errors (PCISME) study in 2001. The 6 countries included the United States, Canada, England, the Netherlands, Australia, and New Zealand. More details about PCISME are provided elsewhere. ${ }^{20}$

In brief, from June to December 2001, 73 primary care physicians in the 6 countries used a secure Internet connection to file 431 anonymous reports of errors observed in practice. A software template (Healix Software; World Health Network, London, UK), piloted in an earlier American study, ${ }^{21}$ systematically gathered free text and fixed-choice descriptions of the incidents (details are available in Appendix 1, which can be found online as supplemental data at http:// www.annfammed.org/cgi/content/full/2/4/317/

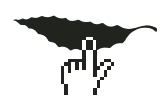
DC1. A list of the of the specific questions physicians answered when posting error reports is displayed in Appendix 1, Table 1). The error-reporting process protected the anonymity of physicians and patients. Human subjects committees in each country, including the Virginia Commonwealth University Institutional Review Board, approved the protocol.

\section{US Component}

This article examines 75 reports filed by the US participants, a convenience sample of 18 family physicians from 5 middle Atlantic, Northeast, and Midwestern states. Characteristics of the physicians are provided in Appendix 1. We examined reports from US physicians only (not those from other countries) because investigators in each country could examine raw data from their country only.

\section{Cascade Analysis}

In the autumn of 2002 we examined the 75 error reports from the US physicians to delineate the sequence of events described in the narratives. To classify the errors reported in these events, we developed a typology at a meeting in July 2002 during which we considered 3 potential methods (including the LINNAEUS taxonomy ${ }^{20}$ ) and arrived at consensus for the following elements.

\section{Errors, Incidents, and Cascades}

We defined the overall story of what went wrong as an incident, and the individual mistakes within the incident as errors. An incident involving multiple errors was designated a cascade if 1 error led causally to another. We counted an action or omission as an error only if it was inherently wrong independently of what transpired before or after. An error setting off other events that were not themselves errors was considered a single error and not a cascade. We defined distal errors as the final or ultimate error in the cascade, such as not receiving treatment for 


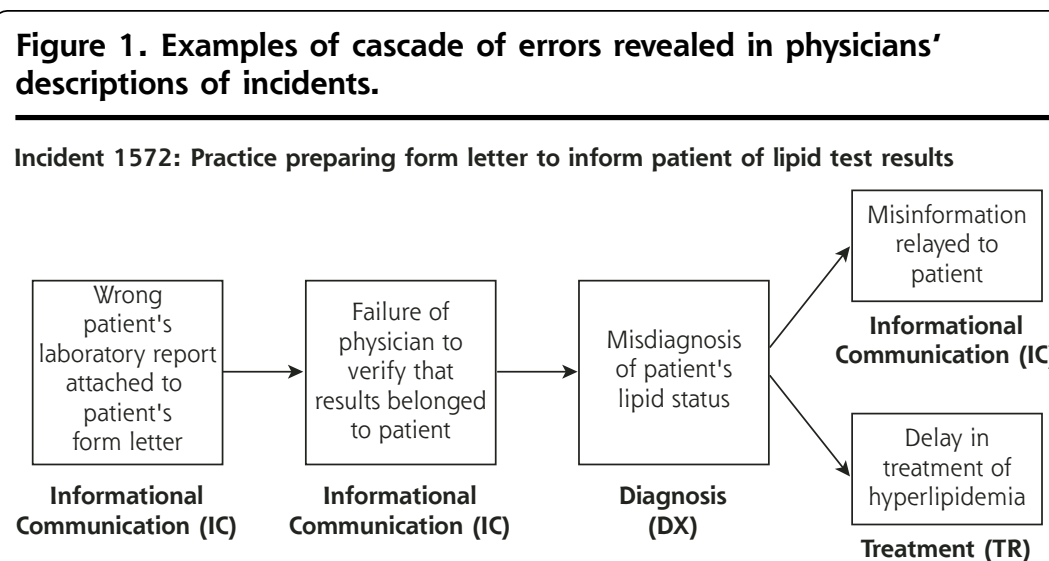

Incident 1558: Hospitalized patient on warfarin develops low blood pressure.

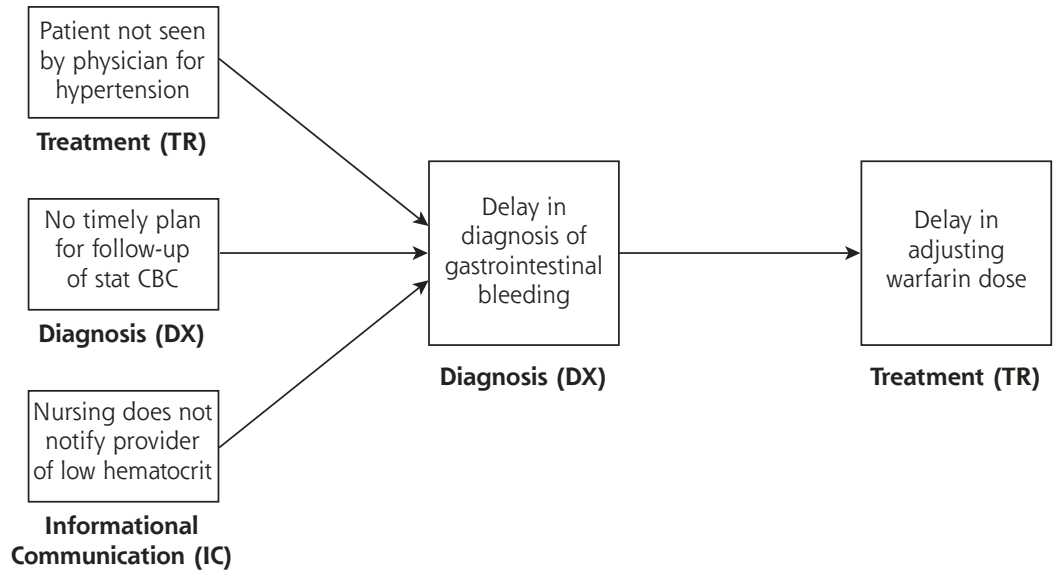

Incident 1516: Patient with suspected nasal fracture sent for x-ray

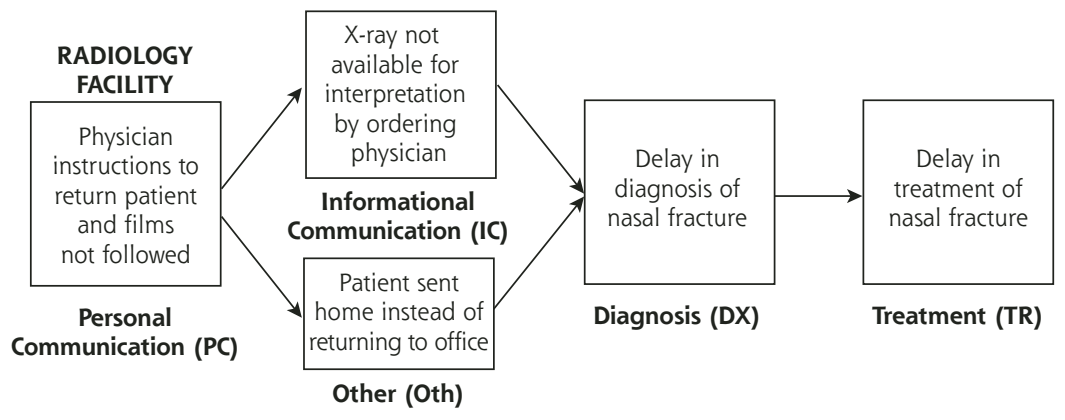

Treatment (TR) = errors in administering treatments, medications, immunizations, and care plans; diagnosis (DX) $=$ errors in screening, diagnostic examination and testing, and interpretation of findings; informational communication (IC) = errors in processing messages, instructions, and medical record data; personal communication (PC) = errors in interpersonal communication among providers and patients; $C B C=$ complete blood count.

tributing to the incident. Contributing factors were counted as errors only if the group consensus was that the contributing factor represented a wrong act (or omission). For example, a specialist refusing to see an ill patient because he lacked a referral form was coded as an error, but the insurance rules requiring the form (a precondition) was not coded as an error. Errors that may have occurred in the incident but that were not reported by the physician, however likely, were not listed.

\section{Consequences}

We defined consequences as the effect of errors on patients. Although errors can affect entities other than patients (eg, providers, health systems, payers), in this analysis we counted only the harms and costs affecting patients. We classified harms into 3 categories: (1) physical injuries (physical health complications from errors during the reporting period), (2) errors that had no reported immediate effect but that heightened the patient's risk for complications after the reporting period (eg, poor control of hypertension), and (3) psychological or emotional injuries (eg, frustration, anger). We did not count potential harms associated with near misses, ${ }^{22}$ ie, errors that could but did not have consequences. In considering costs, we noted whether the patient experienced an ordeal (eg, inconvenience of an unnecessary procedure), lost time, out-ofpocket expenditures, or other opportunity costs, but we did not quantify them.

a disease or not being immunized. The first or underlying errors in the cascades were defined as proximal errors. The chain of errors was arrayed graphically to depict causal relations (Figure 1).

We listed only errors, not all causal or predisposing factors (eg, being hurried, competing demands) con-
We noted both (1) consequences mentioned in the physicians' narratives and (2) those inferred by the investigators based on the incident descriptions. For example, the investigators inferred that a laboratory error necessitating a child to undergo repeat venipuncture would cause physical discomfort for the child and 
frustration and inconvenience for the parents even if these consequences went unmentioned by the physician. These inferred consequences were classified as investigator-observed or investigator-presumed consequences according to whether they were considered self-evident or likely, respectively.

\section{Domains of Patient Care}

We classified each of the errors reported in the 75 incidents under 5 domains of patient care: (1) treatment-errors in administering treatments, medications, immunizations, and care plans; ${ }_{i}$ (2) diagnosis-errors in screening, diagnostic examination and testing, and interpretation of findings, ${ }_{i}$ (3) informational communication-errors in processing messages, instructions, and

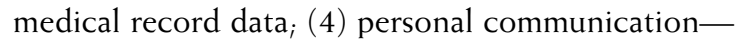
errors in interpersonal communication among providers and patients; or (5) other. We envisioned informational communication errors as those that might be remedied by computers or other information technologies. Personal communication errors, such as not fully explaining to patients the rationale for treatment, have more to do with communication styles and skills.

\section{Data Analysis}

The authors (SHW, AJK, SMD, RJP), who met in person (July 24, 2002; September 3, 2002; October 22, 2002) and examined shared data files by teleconference and e-mail to review each of the 75 incidents, reached unanimous consensus on (1) how many errors occurred, (2) which story elements were errors, (3) the graphical depiction of causal relationships, (4) which of the 5 domains of care best described each error, (5) which consequences were reported by physicians and which were investigator-observed or presumed (see above), and (6) which category of harms or cost best described each consequence. Each investigator independently coded errors and consequences before the meetings. Discrepancies in coding were discussed as a group, and final codes were selected by unanimous agreement. Each cascade was depicted visually and approved by consensus.

After completing the coding, we gathered descriptive statistics on the distribution of errors across the 5 domains of patient care. (In Appendix 1, Table 2 we contrast these results with those produced by the LINNAEUS taxonomy, ${ }^{20}$ showing that the most common error depends on the taxonomy and the unit of analysis.) Through cascade analysis, we traced backward to study the types of errors that occurred more proximally and their patterns and sequences in propagating distal errors. Finally, we examined the distribution of consequences reported by physicians and inferred by investigators.

\begin{tabular}{lc}
\hline \multicolumn{2}{l}{ Table 1. Characteristics of Error Reports (N = 75) } \\
\hline Characteristics & No. (\%) \\
\hline Error related to an individual patient & $73(97)$ \\
Patient characteristics & \\
Age: Less than 18 years & $8(11)$ \\
$18-64$ years & $38(52)$ \\
Above 64 years & $21(29)$ \\
Gender (male/female) & $26 / 44(37 / 63)$ \\
Racial/ethnic minority & $19(26)$ \\
Chronic health condition & $44(60)$ \\
Complex health condition & $34(47)$ \\
Physician familiarity with patient & \\
Very familiar with the patient and their health & $28(38)$ \\
$\quad$ condition(s) & $7(23)$ \\
Never seen the patient before and unfamiliar & \\
Sites of care implicated in reported error & \\
Physician's office & $52(69)$ \\
Hospital & $16(21)$ \\
Laboratory & $5(7)$ \\
Pharmacy & $5(7)$ \\
Telephone contact & $4(5)$ \\
Emergency room & $3(4)$ \\
Nursing home & $2(3)$ \\
Patient's home & $2(3)$ \\
Radiology & $2(3)$ \\
Another place & $2(3)$ \\
\hline
\end{tabular}

\section{RESULTS}

\section{Errors}

Table 1 provides descriptive statistics for the 75 reported error incidents. Of the 88 sites implicated in the narratives, $21 \%$ were hospitals, $69 \%$ were physicians' offices, and $10 \%$ were elsewhere (eg, pharmacies, laboratories, patients' homes).

\section{Cascade Analysis}

The 75 narratives described 184 component errors. Seventeen $(23 \%)$ of the incidents involved a single error (no cascade), but the remaining 58 narratives described a chain of at least $2(33,44 \%), 3(17,23 \%)$, or $4(8,11 \%)$ errors (see examples in Figure 1$)$. The 75 incidents involved 83 proximal errors and 84 distal errors (some incidents involved dual or triple proximal or distal errors). Of the 84 distal errors, 57 (68\%) were treatment errors, 13 (15\%) were errors in diagnosis, and $14(17 \%)$ were errors in communication. More details about the diagnostic and treatment errors are in Appendix 1, Table 3.

We set aside the 17 incidents that did not involve multiple errors (single-error incidents), leaving 58 cascades for analysis. We then examined the proximal errors that precipitated the cascades. For the 45 distal errors that involved treatment (Figure 2), 10 (22\%) were preceded by other errors in treatment, ie, 1 mis- 
Figure 2. Errors precipitating the 45 distal errors in treatment described in the narratives.

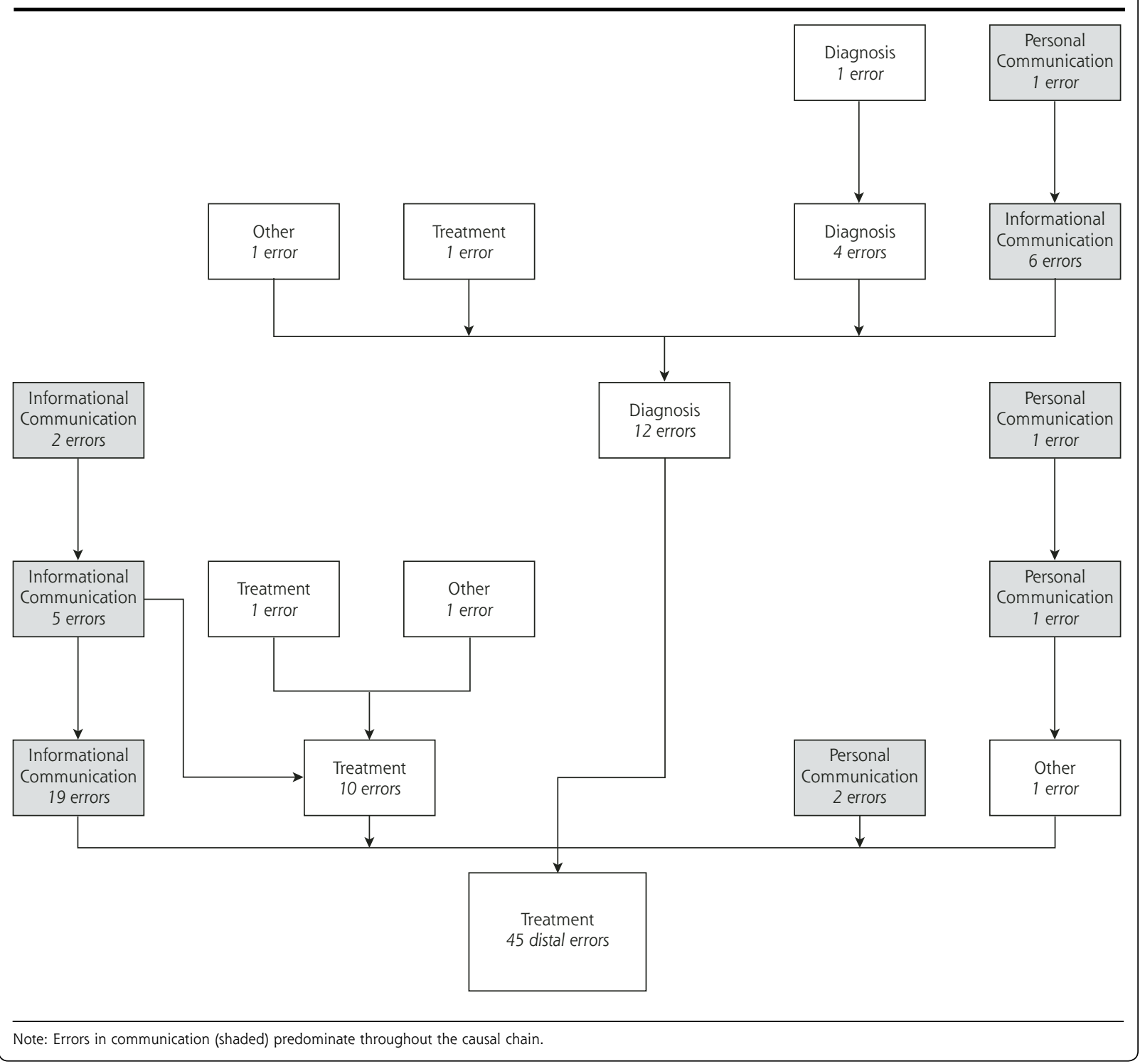

take in treatment giving rise to another. In 12 cases treatment errors were preceded by diagnostic errors, and in 5 of these cases 2 or more diagnostic errors precipitated the treatment error.

The most conspicuous finding, however, was the frequency with which distal errors were precipitated by errors in communication. Although mistakes in treatment and diagnosis accounted for $83 \%$ of distal errors, $80 \%$ of proximal errors consisted of mistakes in communication (Figure 3 ). Fully $67 \%$ of distal treatment errors originated from errors in communication. A similar pattern was seen among the 11 incidents with a distal diagnostic error. Often, multiple errors in communication propagated or converged with each other in precipitating the distal diagnostic or treatment error.
Altogether, errors in communication set off 47 (63\%) of the 75 incidents reported by the physicians.

Of the 64 errors in communication reported by physicians (Appendix 1, Table 4), 57 (90\%) constituted informational miscommunication that is potentially preventable through the use of computers or other information systems. These errors included breakdowns in communication among colleagues and with patients that are potentially avoidable through electronic communication and other strategies $(44 \%)$; misinformation in the medical record that might be prevented by automated data entry $(21 \%)$; breakdowns in processing patient requests and messages that are amenable to electronic message-handling procedures $(18 \%)$; inaccessible medical records that are avoidable with 
Figure 3. Distribution across 5 domains of care for all errors $(\mathrm{N}=184)$ reported in 75 incidents and for proximal (first or underlying) and distal (final or ultimate) errors at either end of the cascades ( $N=83$ and 84 , respectively).

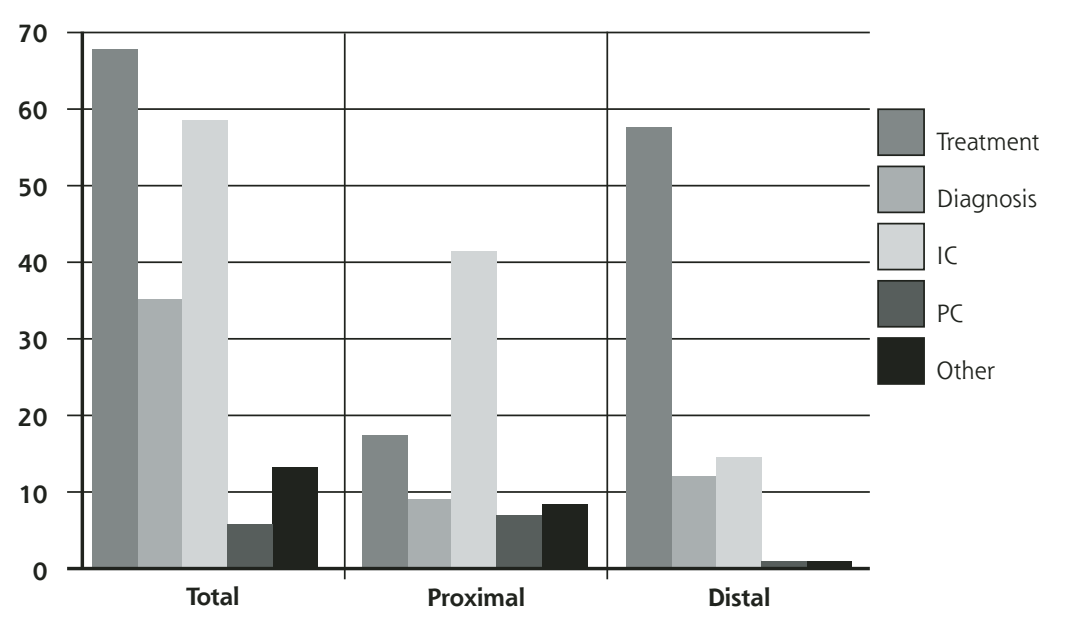

Note: Distal errors predominantly involve treatment, but communication errors predominate at the outset.

Treatment = errors in administering treatments, medications, immunizations, and care plans; diagnosis = errors in screening, diagnostic examination and testing, and interpretation of findings; informational communication (IC) = errors in processing messages, instructions, and medical record data; personal communication (PC) = errors in interpersonal communication among providers and patients.

electronic medical records $(12 \%)$; and the absence of reminder systems $(5 \%)$.

Not all errors could be traced to errors in communication. Nine incidents began with mistakes in diagnosis, and 18 began with treatment errors (Appendix 1, Table 5). Although these errors in clinical judgment and therapy might also have originated from errors in communication or other factors not reflective of judgment, evidence to this effect was absent in the physicians' narratives.

\section{Consequences to Patients}

The physicians described 35 (32 observed, 3 presumed) health consequences in 30 narratives. When asked directly whether the patient was harmed, however, the physicians answered affirmatively in only $13(43 \%)$ cases. Investigator analysis of the physician reports identified 67 additional ways in which patients' health was necessarily (9) or likely (58) affected but went unmentioned by the physicians, and 30 incidents where opportunity costs were likely. Psychological and emotional effects accounted for only $17 \%(6 / 35)$ of the health consequences reported by physicians but $69 \%(46 / 67)$ of the health consequences inferred by investigators (Figure 4). Details about the consequences reported by physicians and inferred by investigators are in the Appendix 1, Table 6.

\section{DISCUSSION}

The patient safety movement currently focuses on errors for which there are available solutions, ${ }^{23,24}$ such as automated prescription entry, ${ }_{1}^{25,26}$ and on other errors that

\section{Figure 4. Consequences to patients as reported by physicians and inferred by investigators.}

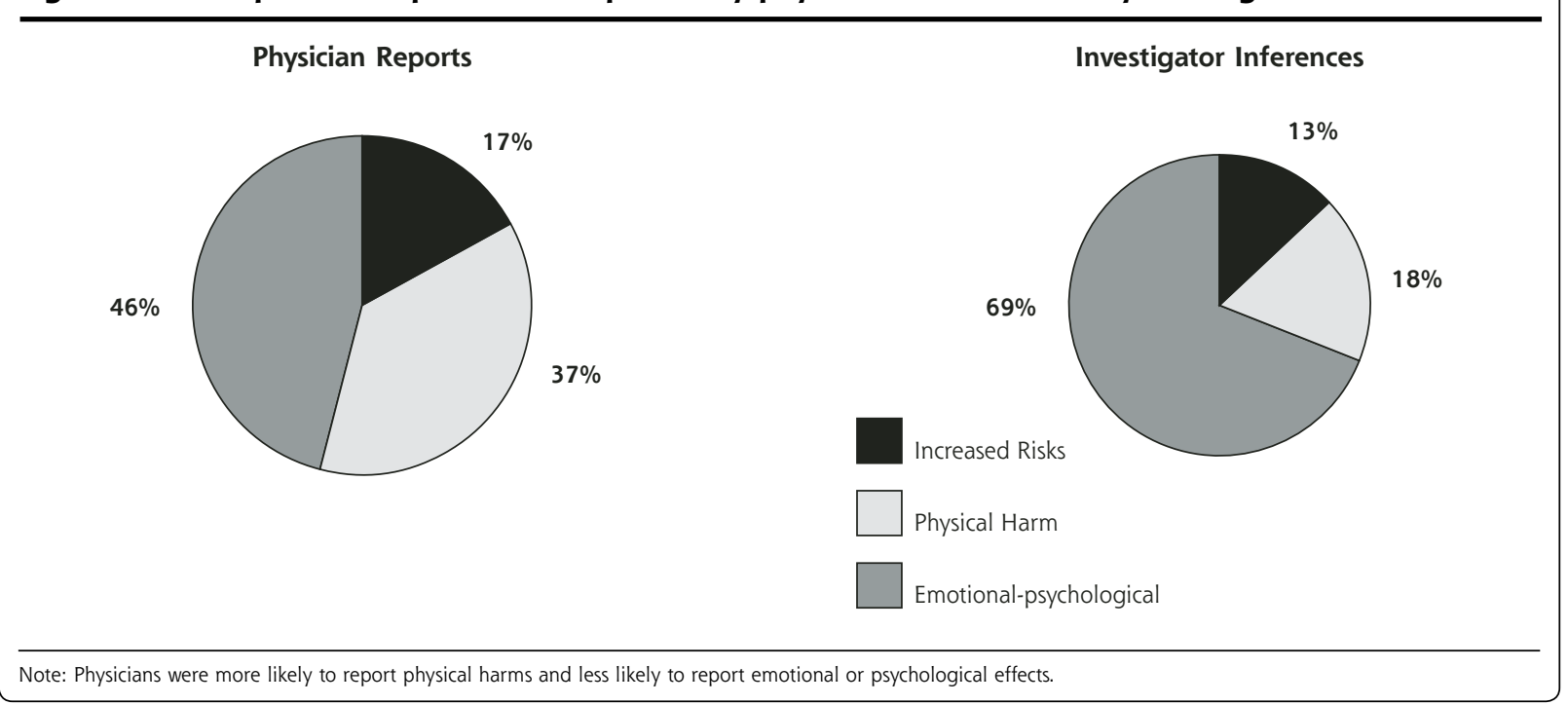


are assumed to be most common or harmful. There is, however, limited epidemiologic research with which to determine the latter. High-quality, generalizable data are lacking, ${ }_{1}^{27}$ and the definition of error itself is argued. ${ }^{28,29}$

Most efforts to quantify errors focus on downstream events, predominantly errors in diagnosis and treatment. Such mistakes, viewed in isolation from their causal origins, appear as clinical misjudgments ${ }^{30,31}$ and inspire interventions designed around skill building, ${ }^{32,33}$ yet the underlying issue may not be misjudgment but the quality of the data on which the judgments are based. The policy importance of overlooking proximal causes is great, because physicians, health care systems, and policy makers, operating from inadequate evidence and the misperceptions it creates may be inattentive to the errors and system defects that threaten patients the most. ${ }^{34-36}$

We found cascade analysis useful in identifying upstream errors that are qualitatively different from distal errors and that imply different solutions. Fully $77 \%$ of the stories in our study involved a chain of individual errors. Recognizing and documenting these causal chains serves several purposes. First, it enhances the quality of error epidemiology by making errors, and not incidents, the unit of analysis. Error epidemiology is skewed by counting an incident once and giving it one name, such as adverse drug event, when it is causally linked to other errors, such as a misdiagnosis or a lost telephone message.

Second, cascade analysis reveals the story line of errors. Summary statistics that tabulate the raw totals of errors within cascades (eg, Appendix 1, Table 2) do not clarify temporal or causal interrelationships, nor do they distinguish the distal errors from those that play a more causal role. In clarifying what really happened, cascade analysis redirects attention (and blame) from the actors involved in the distal error to the circumstances causing proximal events. Although we found that $92 \%$ of the distal errors involved mistakes in diagnosis and treatment, we found that two thirds $(67 \%)$ of these errors were set in motion by errors in communication. In many incidents the most seasoned clinician would repeat the same mistake if given the same, flawed facts.

Third, by identifying underlying upstream causes, cascade analysis suggests solutions to both the index problem and the other errors they propagate. For example, more than $90 \%$ of the errors in communication appeared to be remediable by computers or other information systems. Cascade analysis helps to direct energies and resources toward root causes, but it goes beyond traditional root cause analysis ${ }^{37}$ to identify intermediary errors in the causal chain. Midstream problems that predominate in medical errors and are more amenable to correction than root causes ${ }^{28,38} \mathrm{can}$ be identified through cascade analysis.
The role of root cause (or systems) analysis in understanding medical errors is not new. ${ }^{39}$ Reason's classic model of organizational accidents ${ }^{40}$ (depicted in Appendix 1, Figure 1) recognized that errors ("unsafe acts") are "active failures" that arise from error-producing environmental conditions and that these conditions arise from flawed organizational systems ("latent failures"). Vincent and colleagues ${ }^{41-43}$ expanded Reason's model for application in medicine and introduced a detailed protocol ${ }^{44,45}$ for tracking the causes of clinical incidents. A similar approach was embraced recently by the Institute of Medicine, which advocated such analyses in standardized error reports. ${ }^{46}$

The models published by Reason and Vincent et al placed all errors (unsafe acts) in 1 box (Appendix 1 Figure 1), but they understood that in many incidents the box represents a chain of errors, what Dovey et $\mathrm{al}^{2}$ described as a toxic cascade. Each of these errors can be accompanied by the cadre of precipitants that Reason and Vincent described: latent failures, contributory factors, and absent defenses. Others are currently examining the role of contributing factors in propagating error incidents. ${ }^{47}$ Merging their work with our notion of cascades suggests a more complex and dynamic causal model for medical errors (Figure 5).

We found physicians' reporting to be more useful in describing incidents than in documenting consequences to patients. Physicians appeared reluctant to acknowledge that patients were harmed, even when the harm was mentioned in their narratives. It is unclear whether this represents medicolegal sensitivities or a subtle psychological manifestation of denial. We found that physicians' awareness of consequences focused more on immediate physical consequences and less on psychological and emotional trauma and costs.

This study has several limitations: (1) We doubt that the physician reports were complete, accurate, free of bias, or representative of all errors in primary care. The physicians might not have reported all relevant details or might have suggested precipitants other than the true causes. We did not seek, however, to achieve representativeness or to attribute blame, but rather to test a principle: to demonstrate the notion of cascades beginning with the elements of stories reported by physicians. The same approach could then be used with more fully documented incidents to map out a more comprehensive causal chain. (2) Our cascade analysis focused on errors that seemed to propagate cascades, omitting errors unknown to the investigators and the other conditions (eg, predisposing factors) that allow errors to occur. We did so consciously for purposes of simplicity but recognize that a complete cascade description would include all elements of the causal chain. (3) Our cascades were constructed empiri- 
Figure 5. Analytic construct to incorporate Reason's model of organizational accidents into the notion of cascades.

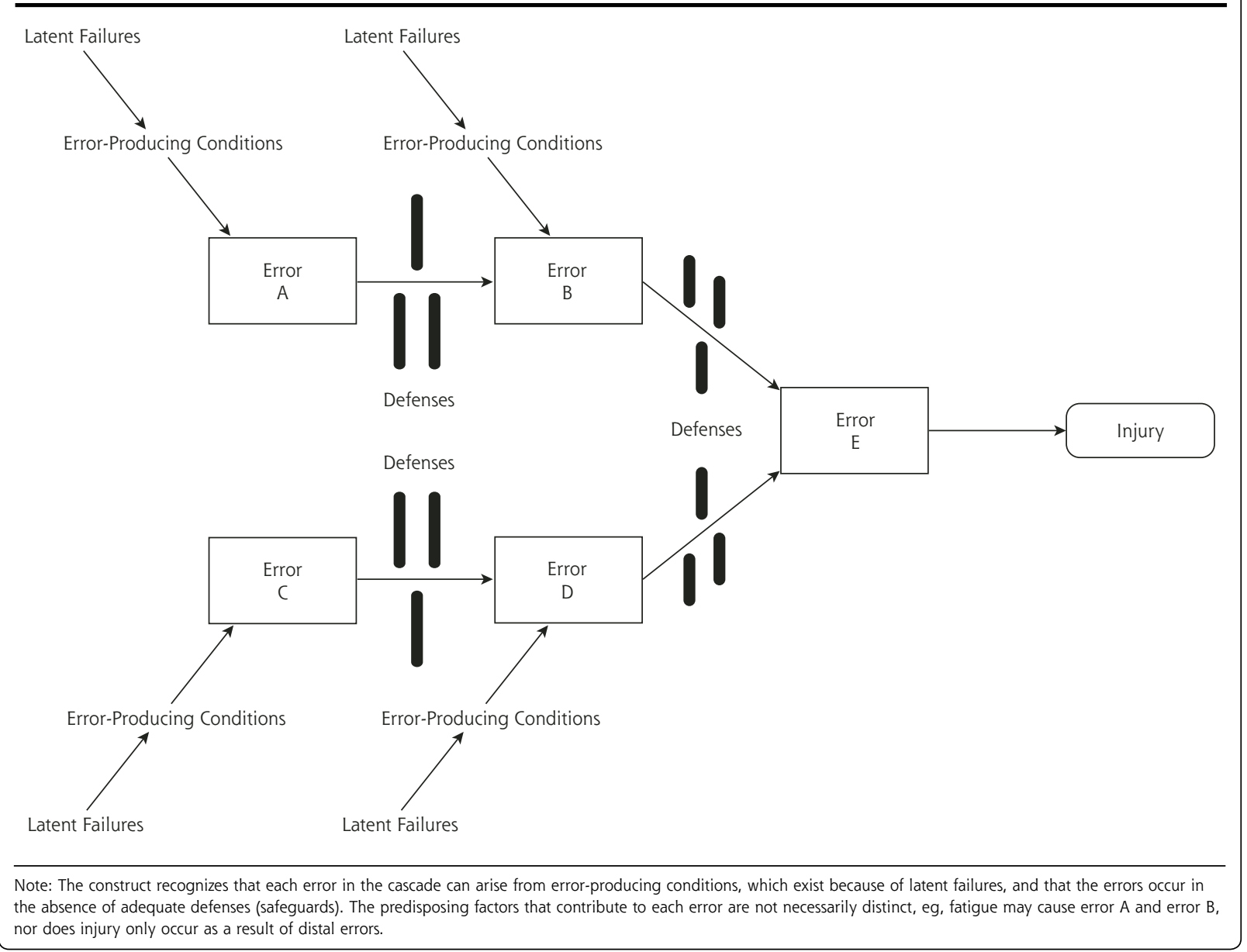

cally from narratives rather than from an independent theoretical construct. (4) We used investigator judgment to infer causal relationships and to assess the likelihood of consequences to patients.

Several research and policy implications emerge from these findings. First, claims about which errors are most common in medicine should be made and interpreted with caution. Second, our experience suggests that epidemiologic studies and policy programs should move away from treating error incidents as single events and should instead use analytic methods, such as cascade analysis, to expose causal relationships and solutions. Third, our findings and those of others ${ }^{48}$ that diagnostic and treatment errors often begin with errors in communication suggest that safety initiatives should focus less on professional interventions to improve clinical judgment and more on management systems to enhance the quality of information transfer. Fourth, amid doubts that an ideal error-reporting system can be developed, it might be more important to focus on whether the system is designed to relate enough of the story line to facilitate cascade and root cause analysis. Our observation that physicians underreport the impact of errors on patients argues against physician reporting as a reliable data source for harms.

The frequent psychological and emotional consequences observed in our study contrasts with the prevailing perception that errors harm patients primarily through improper drug prescriptions and surgical mishaps. ${ }^{7}$ In a separate study involving in-depth interviews of primary care patients, we have shown that consumers' experience of errors is dominated by emotional and psychological trauma more so than physical complications. ${ }^{49}$

The dissonance between this perception and the medical community's preoccupation with the (physical) health complications of errors to some extent may reflect the acuity level in hospitals, where experience with errors has been greatest, that is higher than in the ambulatory setting from which our data derive. But the dissonance between physicians and patients that we observed was entirely in the primary care setting, pointing toward a more fundamental difference 
in perspective. Recent reports ${ }^{50,51}$ highlight the discordant perceptions of the public and physicians regarding medical errors. We conclude that no single lens is adequate and that the views through multiple lenses must be blended to gain a full understanding of the frequency and severity with which errors harm patients

\section{To read or post commentaries in response to this article, see it} online at http://www.annfammed.org/cgi/content/full/2/4/317.

Key words: Medical errors; medication errors; safety management; outcome and process assessment (health care); patient safety; cascade analysis; root cause analysis; primary health care

Submitted September 9, 2003; submitted, revised, December 15, 2003; accepted January 5, 2004

Preliminary results were presented at the annual research meeting of the Academy for Health Services Research and Health Policy, June 23-25, 2002, Washington, DC; and at the 31st Annual Meeting of the North American Primary Care Research Group, October 25-28, 2003, Banff, Alberta, Canada.

Funding support: Supported in part by a grant from the Commonwealth Fund and from grant No. 1R03HS11725-01 from the Agency for Healthcare Research and Quality. Healix software used for physician error reports was provided by World Health Network, London, UK.

Acknowledgments: The authors wish to thank the 18 family physicians in the United States who anonymously provided the error reports analyzed in this study, and the principal investigators from the 5 other countries that participated in the PCISME study (Aneez Esmail, University of Manchester, United Kingdom; Murray Tilyard and Katherine Hall, University of Otago, New Zealand; Meredith Makeham and Michael Kidd, University of Sydney, Australia; Chris van Weel, University Medical Center, the Netherlands; and Walter Rosser, University of Toronto, Canada). We thank Professor Charles Vincent, University College London, and the anonymous reviewers, for their helpful comments on earlier drafts of this manuscript. We thank Tammy Butler for assistance in managing the project.

\section{References}

1. Rosenthal MM, Sutcliffe KM, eds. Medical Error: What Do We Know? What Do We Do? San Francisco, Calif: Jossey-Bass; 2002.

2. American Academy of Family Physicians, Robert Graham Center for Policy Studies in Family Practice and Primary Care. Toxic cascades: a comprehensive way to think about medical errors. Am Fam Phys. 2001;63:847. Also available at: http://www.aafppolicy.org/x161.xml.

3. Cook RI, Woods DD. Operating at the sharp end: the complexity of human error. In: Bogner MS, ed. Human Error in Medicine. Hillsdale, NJ: Lawrence Erlbaum Associates; 1994:255-310.

4. Moray N. Error reduction as a systems problem. In: Bogner MS, ed. Human Error in Medicine. Hillsdale, NJ: Lawrence Erlbaum Associates; 1994:67-91.

5. Nolan TW. System changes to improve patient safety. BMJ. 2000;320:771-773.

6. Mold JW, Stein HF. The cascade effect in the clinical care of patients. N Engl J Med. 1986;314:512-514

7. Kohn LT, Corrigan JM, Donaldson MS, eds. Institute of Medicine. Committee on Quality of Health Care in America. To Err is Human: Building a Safer Health System. Washington, DC: National Academy Press; 2000.
8. Leape LL, Brennan TA, Laird N, et al. The nature of adverse events in hospitalized patients: results of the Harvard Medical Practice Study II. N Engl J Med. 1991;324:377-384.

9. Thomas EJ, Studdert DM, Burstin HR, et al. Incidence and types of adverse events and negligent care in Utah and Colorado. Med Care. 2000;38:261-271.

10. Wilson RM, Runciman WB, Gibberd RW, Harrison BT, Newby L, Hamilton JD. The Quality in Australian Health Care study. Med J Aust. 1995163:458-471.

11. Brennan TA, Localio RJ, Laird NL. Reliability and validity of judgments concerning adverse events suffered by hospitalized patients. Med Care. 1989:27:1148-1158.

12. McDonald CJ, Weiner M, Hui SL. Deaths due to medical errors are exaggerated in Institute of Medicine report. JAMA. 2000;284:93-95.

13. Leape LL. Institute of Medicine medical error figures are not exaggerated. JAMA. 2000;284:95-97

14. Thomas EJ, Studdert DM, Runciman WB, et al. A comparison of iatrogenic injury studies in Australia and the USA. I. Context, methods, casemix, population, patient and hospital characteristics. Int J Qual Health Care. 2000;12:371-378.

15. Brennan TA. The Institute of Medicine report on medical errorscould it do harm? N Engl J Med. 2000;342:1123-1125.

16. Hayward RA, Hofer TP. Estimating hospital deaths due to medical errors: preventability is in the eye of the reviewer. JAMA. 2001;286:415-420.

17. Thomas EJ, Studdert DM, and Brennan TA. The reliability of medical record review for estimating the frequency of medical mistakes. Ann Intern Med. 2002;136:812-816.

18. Vincent CA, Coulter A. Patient safety: what about the patient? Qual Saf Health Care. 2002;11:76-80.

19. Landa AS. Patient safety bill calls for voluntary error reporting. Am Med News. July 1, 2002.

20. Makeham M, Dovey S, County M, Kidd M. An international taxonomy for reporting general practice error in Australia and five other countries. Med J Aust. 2002;177:68-72.

21. Dovey SM, Meyers DS, Phillips RL, et al. A preliminary taxonomy of medical errors in family practice. Qual Saf Hlth Care. 2002;11:233238.

22. Barach P, Small SD. Reporting and preventing medical mishaps: lessons from non-medical near miss reporting systems. BMJ. 2000;320:759-763.

23. Ioannidis JP, Lau JP. Evidence on interventions to reduce medical errors: an overview and recommendations for future research. J Gen Intern Med. 2001;16:325-344

24. Leape LL, Berwick DM, Bates DW. What practices will most improve safety? Evidence-based medicine meets patient safety. JAMA. 2002;288:501-513.

25. Teich JM, Merchia PR, Schmiz JL, Kuperman GJ, Spurr CD, Bates DW. Effects of computerized physician order entry on prescribing practices. Arch Intern Med. 2000;160:2741-2747.

26. Computer Physician Order Entry. Washington, DC: The Leapfrog Group, 2003. Available at http://www.leapfroggroup.org/FactSheets/ CPOE_FactSheet.pdf. Accessed December 11, 2003.

27. Weingart SN, Wilson RM, Gibberd RW, Harrison B. Epidemiology of medical error. BMJ. 2000;320:774-777.

28. Hofer TP, Kerr EA, Hayward RA. What is an error? Eff Clin Pract. 2000;6:261-269.

29. McNutt RA, Abrams R, Aron DC. Patient safety efforts should focus on medical errors. JAMA. 2002;287:1997-2001.

30. Wilson RM, Harrison BT, Gibberd RW, Hamilton JD. An analysis of the causes of adverse events from the Quality in Australian Health Care Study. Med J Aust. 1999;170:411-415. 
31. Flores G, Laws MB, Mayo SJ, et al. Errors in medical interpretation and their potential clinical consequences in pediatric encounters. Pediatrics. 2003;111:6-14

32. Satish $U$, Streufert S. Value of a cognitive simulation in medicine: towards optimizing decision making performance of healthcare personnel. Qual Saf Health Care. 2002;11:163-167.

33. Croskerry P. Cognitive forcing strategies in clinical decisionmaking. Ann Emerg Med. 2003;41:110-120.

34. Runciman WB, Edmonds MJ, Pradhan M. Setting priorities for patient safety. Qual Saf Health Care. 2002;11:224-229.

35. Committee on Quality of Health Care in America. Crossing the Quality Chasm: A New Health System For the 21st Century. Washington, DC: National Academy Press; 2001.

36. Lee TH. A broader concept of medical errors. $N$ Engl J Med. 2002;347:1965-1967.

37. Burroughs TE, Cira JC, Chartock $P$, et al. Using root-cause analysis to address patient satisfaction and other improvement opportunities. Jt Comm J Qual Improv. 2000;26:439-449.

38. Hofer TP, Hayward RA. Are bad outcomes from questionable clinical decisions preventable medical errors? A case of cascade iatrogenesis. Ann Intern Med. 2002;137:327-334.

39. Bagian JP, Gosbee J, Lee CZ, Williams L, McKnight SD, Mannos DM. The Veterans Affairs root cause analysis system in action. Jt Comm J Qual Improv. 2002;28:531-545.

40. Reason JT. Human Error. New York, NY: Cambridge University Press; 1990.

41. Vincent C, Taylor-Adams S, Stanhope N. Framework for analysing risk and safety in clinical medicine. BMJ. 1998;316:1154-1157.

42. Taylor-Adams S, Vincent C, Stanhope N. Applying human factors methods to the investigation and analysis of clinical adverse events. Safety Sci. 1999;31:143-159.
43. Rogers S. A structured approach for the investigation of clinica incidents in health care: application in a general practice setting. $\mathrm{Br}$ J Gen Pract. 2002;52(Suppl):S30-S32.

44. Clinical Risk Unit and Association of Litigation and Risk Management. A Protocol for the Investigation and Analysis of Clinical Incidents. London: Royal Society of Medicine Press; 1999.

45. Vincent C, Taylor-Adams S, Chapman EJ, et al. How to investigate and analyse clinical incidents: Clinical Risk Unit and Association of Litigation and Risk Management protocol. BMJ. 2000;320:777-781.

46. Aspden P, Corrigan JM, Wolcott J, Erickson SM, eds. Committee on Data Standards for Patient Safety. Patient Safety: Achieving a New Standard for Care. Washington, DC: National Academies Press; 2004.

47. Pace W, Harris D, West D, Main D, Fernald D. The nature of ambulatory primary care medical errors that cascade into patient harm: a report from the ASIPS Collaborative. Abstract G6. 31st Annual Meeting of North American Primary Care Research Group, October 25-28, 2003, Banff, Alberta. Available at http://www.napcrg.org/ConferenceHandouts/handouts/ASIPS\%20NAPCRG\%202003\%20Handout $\% 20$ w eb5.pdf. Accessed December 4, 2003

48. Forster AJ, Murff HJ, Peterson JF, Gandhi TK, Bates DW. The incidence and severity of adverse events affecting patients after discharge from the hospital. Ann Intern Med. 2003;138:161-167.

49. Kuzel AJ, Woolf SH, Gilchrist VJ, et al. Patient reports of preventable problems and harms in primary health care. Ann Fam Med 2004;2:333-340.

50. Robinson AR, Hohmann KB, Rifkin Jl, et al. Physician and public opinions on quality of health care and the problem of medical errors. Arch Intern Med. 2002;162:2186-2190.

51. Blendon RJ, DesRoches CM, Brodie M, et al. Views of practicing physicians and the public on medical errors. N Engl J Med. 2002:347:1933-1940. 